\title{
Struvite Stone Formation by Ureolytic Biofilms
}

\section{Authors: Erika J. Espinosa-Ortiz, and Robin Gerlach}

This is a postprint of a chapter that originally appeared in The Role of Bacteria in Urology in 2019.

The final version can be found at DOI: $10.1007 / 978-3-030-17542-96$.

Espinosa-Ortiz, Erika J., Robin Gerlach, "Struvite Stone Formation by Ureolytic Biofilms," The Role of Bacteria in Urology, 2019, Eds: Lange, D. and Scotland, K. Springer Nature, 2019. 61-70.

Made available through Montana State University's ScholarWorks scholarworks.montana.edu 


\title{
Chapter 6
}

\section{Struvite stone formation by ureolytic biofilms}

Erika J. Espinosa-Ortiz and Robin Gerlach

\author{
E. J. Espinosa-Ortiz, PhD; R. Gerlach, PhD, Diplom-Ingenieur \\ Department of Chemical and Biological Engineering, Center for Biofilm Engineering, Montana State \\ University, 366 Barnard Hall Building, Bozeman, MT 59717, USA \\ e-mail: erika.espinosaortiz@montana.edu; robin_g@montana.edu
}




\begin{abstract}
This chapter describes the role ureolytic biofilms (communities of microbes attached to surfaces) play in struvite stone formation in the urinary tract. The formation of struvite stones $\left(\mathrm{MgNH}_{4} \mathrm{PO}_{4} \cdot 6 \mathrm{H}_{2} \mathrm{O}\right)$, commonly known as infection stones, is associated with urinary tract infections, particularly, with ureolytic microorganisms. Establishment of ureolytic biofilms in the urinary tract can result in increased microbial resistance to medical treatment and development of the necessary urine conditions to promote struvite (or other mineral) precipitation possibly leading to stone formation. Ureolytic microorganisms produce urease, an enzyme that breaks down urea $\left(\mathrm{CO}\left(\mathrm{NH}_{2}\right)_{2}\right)$ generating ammonium $\left(\mathrm{NH}_{4}{ }^{+}\right)$and alkalizing urine, which changes urine chemistry to potentially promote struvite and other mineral precipitation. This chapter describes the series of steps involved in biofilm development and struvite precipitation leading to stone formation. Furthermore, this chapter presents an overview of controlled laboratory experiments and computer simulations currently used in different disciplines to study microbe-fluid-mineral interactions. We conclude that an interdisciplinary approach including the disciplines of engineering, mathematics, chemistry, microbiology and medicine will provide a more comprehensive understanding of the process of stone formation in the urinary tract and will ultimately allow for the development of improved management and prevention strategies for infection stones.
\end{abstract}

Key words: struvite stone, infection, biofilm, ureolytic microorganisms 


\section{Formation of struvite stones by ureolytic microorganisms}

Infection stones account for almost $10-15 \%$ of urinary tract stones in the general population. Infection stone formation is one of the most complicated stone diseases due to the association of stone growth with bacterial infections, fast stone growth, high recurrence and tendency to form large aggregates (e.g. staghorn calculi) [1]. Infection stones are comprised of struvite $\left(\mathrm{MgNH}_{4} \mathrm{PO}_{4} \cdot 6 \mathrm{H}_{2} \mathrm{O}\right)$, which is frequently accompanied by calcium phosphate, mostly in the form of carbonate apatite (carbapatite, $\left.\mathrm{Ca}_{10}\left(\mathrm{PO}_{4}\right)_{6} \mathrm{CO}_{3}\right)$. Indeed, the composition of -so called- struvite stones is quite heterogeneous; Flannigan et al. [2] reported that among 121 struvite stones collected, $13.2 \%$ were homogeneous struvite, whereas $86.8 \%$ were heterogenous stones admixed with calcium phosphate $(42.1 \%)$, calcium oxalate $(33.9 \%)$, calcium carbonate $(27.3 \%)$, and uric acid $(5.8 \%)$.

Formation of stones is an intricate process that starts with urine supersaturation (presence of a solute in solution at a higher concentration than that of its own solubility), leading to crystal nucleation and proceeds via crystal growth along with the aggregation of crystals [3]. Supersaturation in urine is a prerequisite for stone formation, however supersaturated urine is also observed in non-stone formers. Supersaturation implies that mineral precipitation is possible, but the presence of inhibitors (e.g. proteins, polysaccharides, etc.) [4] and slow kinetics of precipitation can keep urine supersaturated without significant mineral precipitation or stone growth. In the urinary tract, nucleation of crystals most likely occurs on pre-existing surfaces (heterogeneous nucleation); crystals usually become associated with surfaces ranging from suspended particles in urine (e.g. bacteria, organic substances, cellular debris), to the urothelium, to medical devices (e.g. ureter, catheter) [5]. Formation of microcrystals (roughly those $\leq$ $20 \mu \mathrm{m}$ ) is also observed in non-stone formers, but the crystals are small enough to be excreted through the urinary tract. Thus, for a stone to form, crystals do not only need to be formed but also need to grow and aggregate to be retained within the urinary tract. 
The formation of infection stones depends on urine chemistry, which is driven by two key processes [1]: (i) urine $\mathrm{pH}$; a $\mathrm{pH}>7.2$ is commonly considered the threshold for struvite precipitation, and (ii) supersaturation of urine with respect to the solubility product of magnesium $\left(\mathrm{Mg}^{2+}\right)$, ammonium $\left(\mathrm{NH}_{4}{ }^{+}\right)$ and phosphate $\left(\mathrm{PO}_{4}{ }^{3-}\right)$. Urine normally contains $\mathrm{Ca}^{2+}, \mathrm{Mg}^{2+}$ and $\mathrm{PO}_{4}{ }^{3-}$, but the concentration of $\mathrm{NH}_{4}{ }^{+}$in urine is usually not high enough to promote struvite precipitation. Formation of infection stones seems to be associated with urinary tract infections (UTIS) [1], particularly with the presence of ureolytic (ureahydrolyzing) microorganisms. Ureolytic microorganisms produce the enzyme urease [6], which catalyzes the hydrolysis of urea $\left(\mathrm{CO}\left(\mathrm{NH}_{2}\right)_{2}\right)$ (also known as ureolysis) that leads to the production of ammonia $\left(\mathrm{NH}_{3}\right)$ and carbon dioxide $\left(\mathrm{CO}_{2}\right)$ (Fig. 6.1, Eq. 1). $\mathrm{NH}_{3}$ functions as a Bronsted-Lowry base, generating hydroxide $\left(\mathrm{OH}^{-}\right)$ions, resulting in urine alkalization and production of $\mathrm{NH}_{4}{ }^{+}$(Fig. 6.1, Eq.2), and ultimately triggering struvite precipitation (Fig. 6.1, Eq. 7). $\mathrm{CO}_{2}$ generation during ureolysis leads to the production of carbonate $\left(\mathrm{CO}_{3}{ }^{2-}\right)$ and bicarbonate $\left(\mathrm{HCO}_{3}{ }^{-}\right)$ions (Fig. 6.1, Eq. 3-5). Formation of $\mathrm{CO}_{3}{ }^{2-}$ can promote the precipitation of carbapatite and calcium carbonate (Fig. 6.1, Eq. 6 \& 8), which have been described to occur at pH 6.8 and lower. Carbapatite crystals appear to aggregate as the $\mathrm{pH}$ increases during ureolysis [7].

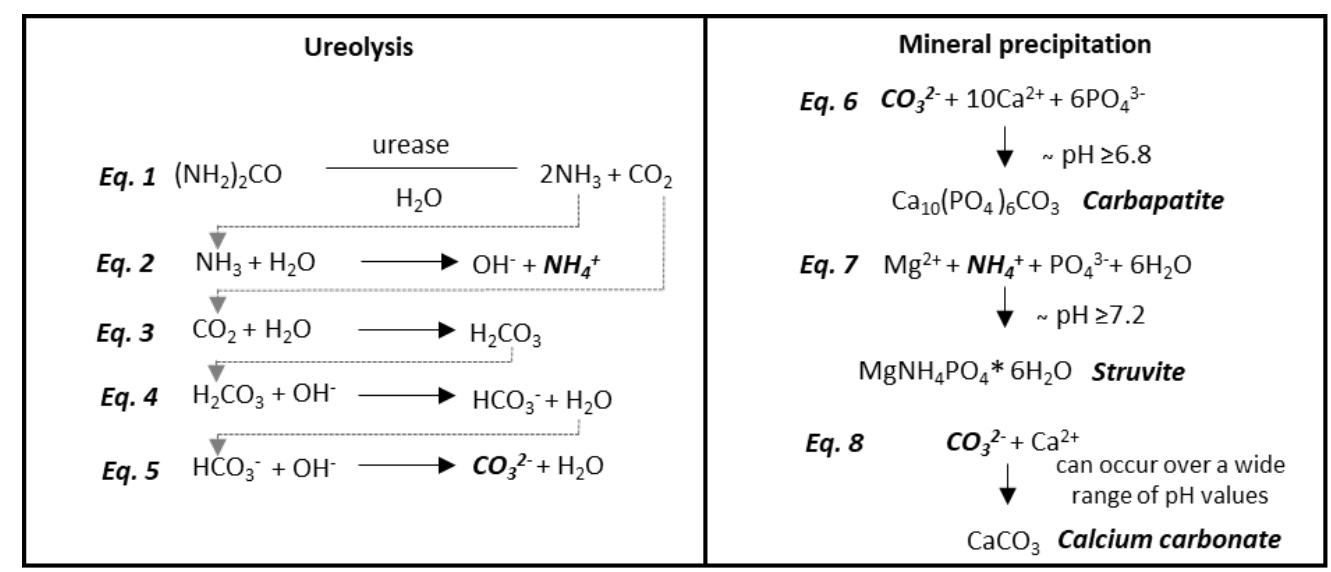

Figure 6.1. Chemical reactions involved in the hydrolysis of urea and the resulting mineral precipitation induced by ureolytic microorganisms.

The particular combination of elevated $\mathrm{NH}_{4}{ }^{+}$concentration and alkaline urine $\mathrm{pH}$ promoting struvite precipitation, is almost exclusively associated with the infection of the urinary tract with ureolytic microorganisms, most commonly Proteus spp., Klebsiella spp., Pseudomonas spp., Staphylococcus spp. 
and some species of $E$. coli $[1,8,9]$. P. mirabilis, a frequent microorganism involved in UTIs [10], has been the most commonly detected microorganism to be associated with struvite formation.

\section{Biofilm development and struvite precipitation}

The presence of pathogens in the urinary tract can lead to biofilm formation, i.e. surface-attached microbial communities embedded in self-produced extracellular polymeric substances (EPS) [11, 12]. Biofilms are generally more resistant to physical and chemical stresses compared to their planktonic counterparts $[11,13,14]$. Biofilm resistance is attributed to the protective effect of the EPS matrix that can hinder the transport of antimicrobials into the biofilm, to the formation of chemical and metabolic gradients within biofilms, and due to other possible resistance mechanisms [13, 15].

Ureolytic biofilm formation in the urinary tract may play a key role in struvite stone formation, as ureolytic microorganisms can provide the appropriate conditions for struvite precipitation, and the EPS matrix can act as additional nucleation site for crystal development. Biofilm development and mineral precipitation in the urinary tract seem to follow a series of steps [16, 17]. (i) attachment of ureolytic microorganisms in the urinary tract: a thin layer is formed comprised of planktonic cells and urinary metabolites, and ureolysis possibly commences; (ii) formation of microcolonies: this is often the first phase of biofilm development accompanied by production of EPS; ureolysis increases the $\mathrm{pH}, \mathrm{NH}_{4}^{+}$and $\mathrm{CO}_{3}{ }^{2-}$ concentrations in the urine; (iii) formation of crystals: primary crystals start forming due to alkaline conditions and increase of $\mathrm{NH}_{4}{ }^{+}$and $\mathrm{CO}_{3}{ }^{2-}$ in urine (supersaturation leads to carbapatite, struvite and possibly calcium carbonate precipitation, Eq. 6.6-6.8); crystals can become entrapped in the EPS matrix; detachment of microbes from the biofilm may occur; (iv) crystal growth/aggregation and secondary nucleation: crystals form and start growing around the attached bacteria and possibly outside the EPS matrix; planktonic bacteria adhere to pre-existing crystals resulting in the formation of more microcolonies that also precipitate minerals; this results in the formation of layers of bacteria encased in minerals; crystal aggregation is influenced by the presence of organic macromolecules in urine (e.g. 
proteins, lipids, glycosaminoclycans), which can inhibit or promote crystal aggregation [18]; (v) stone formation is the result of repeated cycles of the previous steps (bacterial attachment, formation of microcolonies/biofilms and growth/aggregation of crystals) to integrate minerals within the bacterial biofilm, and vice versa.

The inherent heterogeneous structural, chemical and biological nature of biofilms [19] influences the biomineralization process taking place in the urinary tract (Figure 6.2). Urine flow and chemistry vary spatially in the urinary tract; ureolytic microorganisms hydrolyze urea, generating $\mathrm{NH}_{4}{ }^{+}$, changing the local urine saturation; the natural heterogeneity of biofilms [19] creates heterogeneities, including gradients of $\mathrm{NH}_{4}{ }^{+}$concentration, and induces mineral precipitation within the biofilm (Figure 6.2). Urea concentration heterogeneities arise in biofilms due to reaction-diffusion interactions; urea concentration decreases with depth into the biofilm as ureolysis occurs. Oversaturation with respect to minerals such as struvite occurs within and around biofilms owing to the production of $\mathrm{NH}_{4}{ }^{+}$, carbonates, hydroxyl ions, etc. to increase the saturation index to greater than 0 . As the biofilm grows thicker more highly saturated zones develop, which increase the likelihood of mineral precipitation in and around biofilms. Mineral precipitation can potentially occur rapidly at the biofilm-urine interface, as the external flow of urine efficiently transports ions to the biofilm [20].

Figure 6.2. Biofilm induced struvite precipitation. (A) Ureolytic biofilm cross-section in the urinary tract with continuous urine external flow. Ureolytic microorganisms hydrolyze urea, which results in an increase of $\mathrm{pH}$ values as well as ammonium $\left(\mathrm{NH}_{4}{ }^{+}\right)$and carbonate $\left(\mathrm{CO}_{3}{ }^{2-}\right)$ concentrations in the biofilm and the urine. Minerals form and become entrapped inside and around the microbial biofilm. (B) Shear stress from the urine flow can stretch and deform the biofilm. (C) Transport of urea within the biofilm occurs via diffusion; ureolysis within the biofilm decreases urea concentration inside the biofilms and induces heterogeneity. (D) Certain areas within and around the biofilm become oversaturated with respect to struvite due to the production of $\mathrm{NH}_{4}{ }^{+}$ (saturation index, $\mathrm{S}>0$ ); as the biofilm grows thicker areas of supersaturated environment increase. (E) As a result of oversaturation within the biofilm, it is more likely for minerals to precipitate. Mineral precipitation can occur rapidly at the biofilm-urine interface, as the external flow of urine efficiently transports ions to the biofilm surface. This figure was modified based on the results from a mathematical model of biofilm-induced calcite precipitation developed by Zhang and Klapper [20]. Figured modified and reproduced from Zhang and Klapper [20], with permission from the copyright holders, IWA Publishing.

A)

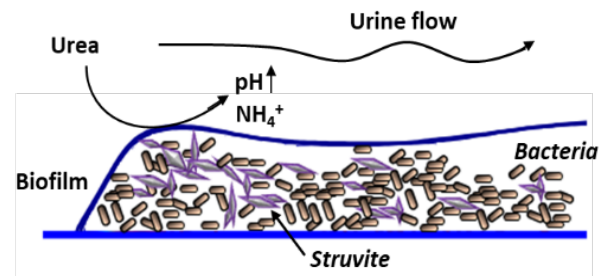

B)

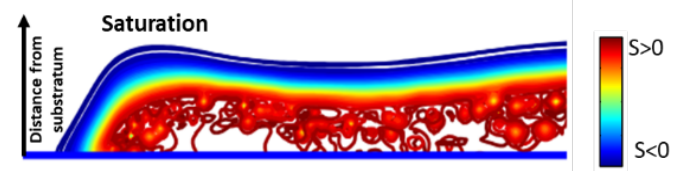

C)

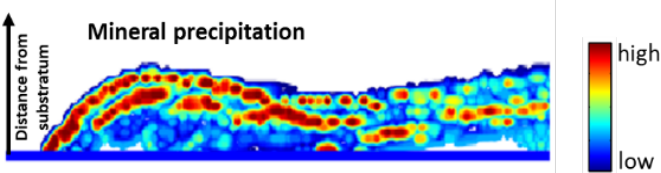

D)

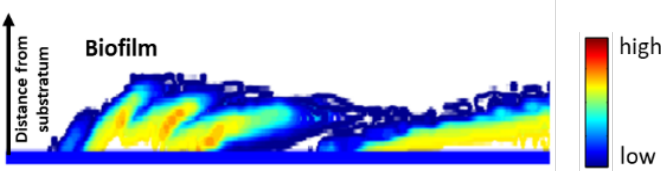

E)

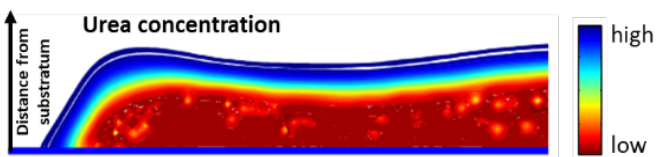




\section{Investigation of struvite stone formation using in vitro and in silico techniques}

As outlined, infection stone formation is an intricate multi-step process influenced by physicochemical, biochemical and physiological factors. Due to the complexity of biofilm development combined with mineral precipitation in the urinary tract, in vivo observations of stone formation are hitherto very challenging. The use of controlled laboratory experiments (in vitro) along with computer simulations (in silico) is an attractive alternative to investigating and ultimately controlling stone formation. In vitro and in silico experiments indeed allow for the study of microbe-mineral interactions at the required spatial and temporal resolution relevant to stone formation. Understanding key microbemineral interactions is anticipated to be a key in the development of new treatments and management strategies for struvite stones.

Controlled laboratory experiments such as batch and continuous flow systems have been used to investigate struvite stone formation and the effect of different urine conditions on stone development. Batch experiments have been performed to evaluate (i) the effect of inhibitor or promoter substances on struvite crystallization [7, 21, 22], (ii) the effect of urease inhibitors [23], (iii) the influence of substances potentially inhibiting microbial colonization and biofilm development by uropathogens [24-26], and (iv) the resistance of materials to encrustation [27]. However, batch experiments generally do not simulate the flow conditions present in the urinary tract, and generally do not allow for long-term experimentation and assessments. Continuous flow systems allow to simulate the hydraulic conditions in the urinary tract and -if designed properly- for real-time observations over extended periods of time. Flow systems have been mostly used to test ureteral stents, antimicrobials and precipitation-inhibitors (both compounds and devices/materials) $[28,29]$. Due to demonstrated reproducibility of results, the Center for Disease Control (CDC) biofilm reactor [30] has been suggested to be used for the evaluation of urological device materials

[28]. The CDC reactor allows for the observation of biofilm growth and mineral precipitation over time under tightly controlled conditions using removable coupons (Figure 6.3A). Flow systems have also been 
developed to test the resistance of different biomaterials used in urinary tract devices against colonization and encrustation (e.g. silicone, polyurethane, Percuflex) [29]; flow systems allow for the exposure of stent devices to flows similar to those in the urinary tract (Figure 6.3B). Hobbs et al. [31] developed an in vitro laboratory model to investigate infection stone formation. The model simulates the urinary tract system using a series of analog components: CDC reactors as kidney and bladder analogues, tubing and glass capillaries simulating the ureter, and sponge coupons representing the porous structure of the kidneys. This system indeed allows for the real-time observation of biofilm formation and mineral precipitation (Figure $6.3 \mathrm{C}$ ). The CDC reactor used as kidney analog allows for sampling of the coupons over time; biofilm-mineral composites accumulate on the coupons as a result of ureolysis induced by ureolytic microorganisms in the reactor; glass capillaries integrated in the "ureter" line allow for microscopic observations over time to assess bacterial migration or mineral precipitation.

(A) CDC reactor

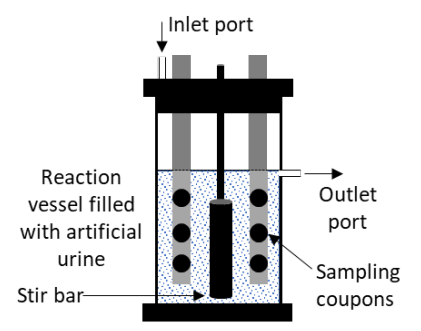

(B) Dynamic encrustation system

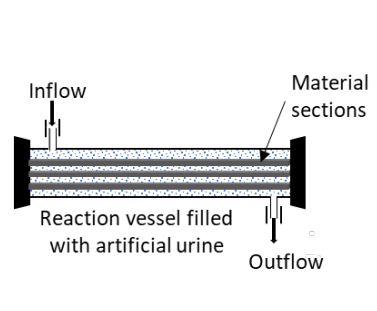

(C) Laboratory model mimicking urinary tract system

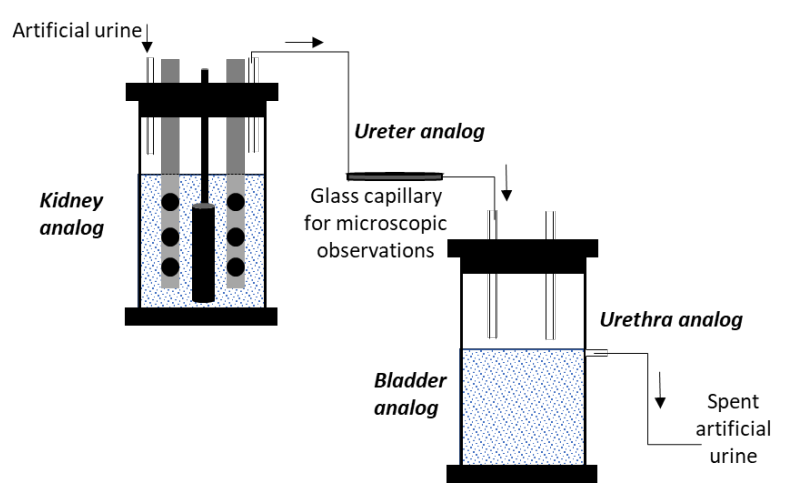

Figure 6.3. Common continuous flow systems used to study stone formation and to test urological device materials.

Investigation of biofilm formation and mineral precipitation in the urinary tract should consider the effect of physicochemical factors including reaction (e.g. ureolysis and precipitation), transport (e.g. advection and diffusion), and hydrodynamics (e.g. fluid flow and shear stress). Furthermore, the viscoelasticity and mechanical properties of the biofilm-mineral composites should be considered when investigating mineral precipitation in infected urinary tract systems. As stated above, biofilms are nonuniform systems with structural, biological and chemical heterogeneity; moreover, biofilms in the urinary 
tract are subjected to fluctuating conditions, such as variations in urine flow and urine chemistry [20]. Quantitative descriptions of urine flow and urine chemistry can be obtained using mathematical modeling along with the simulation of biofilm development and mineral precipitation similarly to work done in the development of engineered biomineralization technologies [32-37].

Reactive transport modeling is a tool commonly used in engineering that allows for the analysis of coupled physical, chemical and biological processes [38]. An example of a user-friendly modeling program that can be used to model reactive transport is COMSOL Multiphysics ${ }^{\circledR}$ software (a finite element framework, COMSOL Inc., Burlington, MA, USA). Connolly et al. [35] used this software to estimate biofilm-specific kinetics of ureolytic biofilms (E. coli MJK2) in flow systems. Estimating ureolysis biofilmkinetics along with other tools to characterize biofilms (e.g. confocal microscopy) can aid in understanding local chemical gradients in ureolytic biofilms. Hence, determining biofilm-specific kinetics can provide a more accurate representation of biofilms in flow systems, for example, development of ureolytic biofilms on urethral catheters [39].

Geochemical modeling software can simulate the saturation conditions of aqueous solutions (e.g. urine) under a variety of conditions and can predict the likelihood of precipitation. Geochemical modeling estimates the saturation state of a system by considering the chemical species in solution and the influence of solid phases. Common geochemical modeling packages are Visual MINTEQ [40] and PHREEQC [41]. These computer-based models can be used to simulate saturation conditions, $\mathrm{pH}$ and ionic strength in urine, and thus predict the potential for mineral (e.g. struvite) precipitation [42], which could lead to stone formation. Combinations of different modeling tools (e.g. COMSOL-PHREEQC) [43] can provide an insight into systems as complex as the urinary tract, in which formation of ureolytic biofilms under flow conditions (urine) along with mineral precipitation is occurring, taking into account urine chemistry and the changing hydrodynamics. 


\section{Summary}

The formation of struvite stones $\left(\mathrm{MgNH}_{4} \mathrm{PO}_{4} \cdot 6 \mathrm{H}_{2} \mathrm{O}\right)$, also known as infection stones, is typically associated with urinary tract infections, particularly, with ureolytic microorganisms. These microorganisms hydrolyze urea, produce ammonium $\left(\mathrm{NH}_{4}^{+}\right)$and potentially increase the urine $\mathrm{pH}$. This process, in turn can affects urine chemistry and can promote struvite and other mineral precipitation. Ureolytic biofilm development in the urinary tract (e.g. on implanted devices) can provide the conditions necessary for struvite precipitation and stone formation. Factors that influence stone formation, and that need to be considered when investigating infection stone formation include: (i) the structural, chemical and biological heterogeneity of biofilms, (ii) urine chemistry and its effect on mineral precipitation and biofilm formation; (iii) presence of modulators in urine (inhibitors or promoters of crystal growth and aggregation, e.g. organics), and (iv) the hydrodynamic conditions (flow) in the urinary tract. Controlled experiments and computer simulations can aid in better understanding the microbe-fluid-mineral interactions occurring within ureolytic biofilms in the urinary tract system. A more comprehensive understanding of stone formation is predicted to ultimately lead to the development of improved management and prevention strategies for infection stones.

\section{Acknowledgements}

This work was supported by the Montana University System Research Initiative (51040-MUSRI2015-03) and a grant from Montana NASA EPSCoR Research Infrastructure Development. This chapter is dedicated to J.W. (Bill) Costerton and Mark E. Shirtliff who dedicated their lives to biofilm research and teaching. 


\section{References}

1. Bichler, K.H., et al., Urinary infection stones. Int. J. Antimicrob. Agents, 2002; 19(6):488-498.

2. Flannigan, R.K., et al., Evaluating factors that dictate struvite stone composition: A multi-institutional clinical experience from the EDGE Research Consortium. Can. Urol. Assoc. J., 2018; 12(4): 131-136.

3. Finlayson, B., Physicochemical aspects of urolithiasis. Kidney Int., 1978; 13(5): 344-360.

4. Fleisch, H., Inhibitors and promoters of stone formation. Kidney Int., 1978; 13(5): 361-371.

5. Finlayson, B. and F. Reid, The expectation of free and fixed particles in urinary stone disease. Invest. Urol., 1978; 15(6): 442-448.

6. Mobley, H.L. and R.P. Hausinger, Microbial ureases: significance, regulation, and molecular characterization. Microbiol. Rev., 1989; 53(1): 85-108.

7. Prywer, J., E. Mielniczek-Brzóska, and M. Olszynski, Struvite crystal growth inhibition by trisodium citrate and the formation of chemical complexes in growth solution. J. Cryst. Growth, 2015; 418: 92101.

8. Golechha, S. and A. Solanki, Bacteriology and chemical composition of renal calculi accompanying urinary tract infection. Indian J. Urol., 2001; 17(2): 111-117.

9. Thompson, R. and T. Stamey, Bactriology of infected stones. Urology, 1973. 2(6): 627-633.

10. Schaffer, J.N. and M.M. Pearson, Proteus mirabilis and Urinary Tract Infections. Microbiol. Spectr., 2015; 3(5): 10.1128/microbiolspec.UTI-0017-2013.

11. Flemming, H.-C. and J. Wingender, The biofilm matrix. Nat. Rev. Microbiol., 2010; 8: 623-633.

12. Jacobsen, S.M. and M.E. Shirtliff, Proteus mirabilis biofilms and catheter-associated urinary tract infections. Virulence, 2011; 2(5): 460-465.

13. Stewart, S. and M.J. Franklin, Physiological heterogeneity in biofilms. Nat. Rev. Microbiol., 200;. 6(3): 199-210.

14. Nickel, J.C., et al., Bacterial biofilms: influence on the pathogenesis, diagnosis and treatment of urinary tract infections. J. Antimicrob. Chemother., 1994(Suppl A:31-41).

15. Mah, T.-F.C. and G.A. O'Toole, Mechanisms of biofilm resistance to antimicrobial agents. Trends Microbiol., 2001; 9(1): 34-39.

16. Flannigan, R., et al., Renal struvite stones--pathogenesis, microbiology, and management strategies. Nat. Rev. Urol., 2014; 11(6): 333-41.

17. Tenke, P., et al., Update on biofilm infections in the urinary tract. World J.Urol., 2012; 30(1): 51-57.

18. Aggarwal, K.P., et al., Nephrolithiasis: Molecular mechanism of renal stone formation and the critical role played by modulators. BioMed Res. Int., 2013; 2013: ID 292953.

19. Stewart, P.S. and M.J. Franklin, Physiological heterogeneity in biofilms. Nat. Rev. Microbiol., 2008; 6: 199-210.

20. Zhang, T. and I. Klapper, Mathematical model of biofilm induced calcite precipitation. Water Sci. Technol., 2010; 61(11): 2957-2964.

21. Chauhan, C.K. and M.J. Joshi, In vitro crystallization, characterization and growth-inhibition study of urinary type struvite crystals. J. Cryst. Growth, 2013; 362: 330-337.

22. Olszynski, M., J. Prywer, and E. Mielniczek- Brzóska, Inhibition of struvite crystallization by tetrasodium pyrophosphate in artificial urine: chemical and physical aspects of nucleation and growth. Cryst. Growth Des., 2016; 16(6): 3519-3529.

23. Jones, D.S., J. Djokic, and S.P. Gorman, Characterization and optimization of experimental variables within a reproducible bladder encrustation model and in vitro evaluation of the efficacy of urease inhibitors for the prevention of medical device-related encrustation. J. Biomed. Mat. Res. Part B: Appl. Biomat., 2006; 76B(1): 1-7.

24. O'May, C., et al., Cranberry derivatives enhance biofilm formation and transiently impair swarming motility of the uropathogen Proteus mirabilis HI4320. Can. J. Microbiol., 2016; 62(6): 464-474. 
25. Rajasekharan, S.K., et al., Burdock root extracts limit quorum-sensing-controlled phenotypes and biofilm architecture in major urinary tract pathogens. Urolithiasis, 2015. 43(1): 29-40.

26. Salini, R., et al., Inhibition of quorum sensing mediated biofilm development and virulence in uropathogens by Hyptis suaveolens. Antonie van Leeuwenhoek, 2015. 107(4): 1095-1106.

27. Venkatesan, N., et al., Effect of uropathogens on in vitro encrustation of polyurethane double J ureteral stents. Urol. Res., 2011; 39(1): 29-37.

28. Gilmore, B.F., et al., Validation of the CDC biofilm reactor as a dynamic model for assessment of encrustation formation on urological device materials. J. Biomed. Mat. Res. Part B: Appl. Biomat., 2010; 93B(1): 128-140.

29. Gorman, S.P., et al., Design and validation of a dynamic flow model simulating encrustation of biomaterials in the urinary tract. J. Pharm. Pharmacol., 2003. 55(4): 461-468.

30. Goeres, D.M., et al., Statistical assessment of a laboratory method for growing biofilms. Microbiol., 2005; 151(3): 757-762.

31. Hobbs, T., et al., Evaluation of biofilm induced urinary infection stone formation in a novel laboratory model system. J. Urol., 2018; 199(1): 178-185.

32. Hommel, J., et al., Finding a balance between accuracy and effort for modeling biomineralization. Energy Procedia, 2016; 97: 379-386.

33. Phillips, A.J., et al., Fracture sealing with microbially-induced calcium carbonate precipitation: A field study. Environ. Sci. Technol., 2016. 50(7): 4111-4117.

34. Hommel, J., et al., A revised model for microbially induced calcite precipitation: Improvements and new insights based on recent experiments. Water Resour. Res. 2015. 51(5): 3695-3715.

35. Connolly, J.M., et al., Estimation of a biofilm-specific reaction rate: kinetics of bacterial urea hydrolysis in a biofilm. Npj Biofilms Microbiom., 2015; 1: 15014.

36. Ebigbo, A., et al., Darcy-scale modeling of microbially induced carbonate mineral precipitation in sand columns. Water Resour. Res., 2012; 48: W07519.

37. Ebigbo, A., et al., Modelling biofilm growth in the presence of carbon dioxide and water flow in the subsurface. Adv. Water Resour., 2010; 33(7): 762-781.

38. Steefel, C.I., D.J. DePaolo, and P.C. Lichtner, Reactive transport modeling: An essential tool and a new research approach for the Earth sciences. Earth Planet. Sci. Lett., 2005; 240(3): 539-558.

39. Morris, N.S., D.J. Stickler, and R.J. McLean, The development of bacterial biofilms on indwelling urethral catheters. World J.Urol., 1999; 17(6): 345-350.

40. Gustafsson, J.P. Visual MINTEQ 3.1. 2000; Available from: https://vminteq.Iwr.kth.se/.

41. Parkhurst, D.L. and C.A.J. Appelo, User's guide to PHREEQC (Version 2) : a computer program for speciation, batch-reaction, one-dimensional transport, and inverse geochemical calculations, in Water-Resources Investigations Report. 1999.

42. Ronteltap, M., M. Maurer, and W. Gujer, Struvite precipitation thermodynamics in source-separated urine. Water Res., 2007; 41(5): 977-984.

43. Nardi, A., et al., Interface COMSOL-PHREEQC (iCP), an efficient numerical framework for the solution of coupled multiphysics and geochemistry. Comput. Geoscie., 2014; 69: 10-21. 